\title{
Introduction \\ Ice Fog, Ice Clouds, and Remote Sensing
}

\author{
Ismail GultePe $^{1}$ and Andrew J. Heymsfield ${ }^{2}$
}

Developing a better understanding of ice fog and ice clouds, utilizing remote sensing and in situ observations, is important for improving numerical weather predictions (NWPs) and climate simulations of these events. Low visibility conditions due to low-level ice clouds (including ice fog) are a societal hazard, affecting infrastructure and human life-for example, transportation, aviation, marine environments, and overall sporting activities. In this context, hazards are considered as processes that produce danger to human life and infrastructure.

Cold fog and ice clouds are important components of the atmospheric boundary layer (ABL) processes that include nucleation of ice crystals, radiation effects on ice crystal growth, mixing processes, physical parameterizations, autoconversion processes, synoptic scale cooling processes, and surfaceocean-atmosphere interactions. Due to the complexity of these processes and their nonlinear interactions, our understanding of cold fog and ice clouds still remains incomplete and complex in its physics. Considering ice fog as an ice cloud touching the Earth's surface suggests that variability and scale issues are also important for their predictions; therefore, their impact on NWP predictions and climate change analysis is still a premature subject.

This special issue of the Journal of Pure and Applied Geophysics (PAGEOPH) contains 14 papers related to ice fog/cloud physics and dynamics, instruments used for their measurements, ice cloud

1 Cloud Physics and Severe Weather Research Section, Meteorological Research Division, Environment Canada, Toronto, ON M3H5T4, Canada. E-mail: ismail.gultepe@canada.ca

2 Mesoscale and Microscale Meteorology Laboratory, NCAR, Boulder, CO 80523, USA. modeling, visibility, precipitation, fog climatology, and cloud remote sensing. Results discussed in this special issue are generated by research efforts among multinational team efforts, conducted globally. Results from the following international projects are included in this special issue: The MATERHORN (Mountain Terrain Atmospheric Modeling and Observations; Fernando et al. 2015) Project and SAAWSO (Satellite Applications for Arctic Weather for SAR (Search and Rescue) Operations; Gultepe et al. 2016a) Project. These projects have demonstrated state of the art research that was planned with various new instrumental platforms measuring highimpact weather conditions. New work on ice formation and evolution in clouds and precipitation is summarized by Baumgardner et al. (2016), which provides a comprehensive exposition of ice clouds, ice fog, and ice precipitation that utilizes novel instruments, observations, numerical modeling techniques, and current challenges for predictions in the future.

The primary processes within the atmospheric boundary layer that influence cold fog and ice cloud formation, development, and dissipation are related to various physical, radiative, and dynamical processes, as well as chemical properties of ice nuclei (IN). These processes and related parameters need to be further studied and evaluated to better understand the ABL ice cloud characteristics, and these can be summarized as follows:

\section{- Microphysical processes/algorithms}

Microphysical processes producing ice particle shapes, size, and number concentration are related to the vertical velocity field, vorticity, and turbulence, as well as chemical compositions of fog/cloud nuclei. These processes use various 
assumptions for physical and empirical parameterizations (Gultepe et al. 2016b, c; McMillen and Steenburgh 2015). As a result, microphysical processes are usually parameterized and their use for simulations should be carefully considered in models that generate cloud ice water content and precipitation.

Microphysical schemes as bulk schemes or detailed bin schemes are chosen based on the goals of the study and computer time involved in the simulations. The new predicted particle properties (P3) scheme (Morrison and Milbrandt 2015) developed is based on the prediction of bulk properties for a single ice-phase category, in contrast to the traditional approaches of separating ice crystals into various predefined species (Morrison et al. 2015). This new scheme can be used for ice fog or ice cloud studies in boundary layer applications. Ice fog or only ice clouds in stable atmospheric conditions can have a specific ice crystal type. Milbrandt and Morrison (2016) used the P3 scheme to be applied for multiple shape categories and this can be considered for the ABL ice clouds or ice fog visibility studies when an anthropogenic nuclei contribution is developed for applications.

- Nucleation processes and chemical composition

Nucleation processes are related to ice nuclei (IN) or cloud condensation nuclei (CCN), nuclei chemical composition, and particle size distributions (PSD). Murray et al. (2012) showed that chemical compositions of ice crystals and ice crystal PSD (or bulk total number concentration of IN $\left(N_{\mathrm{it}}\right)$ ) have a large variability temperature $(T)$ and ice supersaturation $\left(S_{\mathrm{i}}\right)$, among others; usually $N_{\mathrm{it}}$ is found to be less than about $100 \mathrm{~L}^{-1}$. On the other hand, Lawson et al. (2006) and Gultepe et al. (2016b) stated that during low-level ice clouds/ice fog, $N_{\text {it }}$ can reach up to $1000 \mathrm{~L}^{-1}$. This shows that $N_{\mathrm{it}}$ parameterizations for visibility and fog prediction are needed to be further evaluated for ice fog and ice cloud IWC, $N_{\mathrm{i}}$ and Vis predictions.

- Autoconversion of ice crystals and ice crystal precipitation

Autoconversion of cloud/fog ice particles to other particle types and deposition as precipitation are important for cloud physical properties and precipitation. Ice fog or ice clouds with low optical densities usually dissipate after the mixing of dry air, a light precipitation occurrence, or solar radiative heating (Gultepe et al. 2015, 2016a). Presently, ice clouds are described in NWPs with an assumed autoconversion threshold size of 200-300 $\mu \mathrm{m}$ for ice crystals. This size is similar to a typical characteristic size of $10-15 \mu \mathrm{m}$ fog droplet found in warm fog. This shows that the ice cloud or ice fog microphysical structure is a strong function of the specified PSD, critical particle size, and crystal shape. New developments in microphysical schemes presently try to use detailed physical processes to generate precipitation that is different from the assumed threshold values for autoconversion processes and prescribed particle shape assumptions (Harrington et al. 2013a, b). These assumption need to be examined carefully for ice fog and ice clouds, because they do not have large ice crystal sizes.

- Radiative fluxes and particle growth

In-cloud processes that include ice crystal growth usually do not include net radiation effects on the ice particle growth. This leads to either an underestimation or overestimation of particle growth rates, depending on the duration of the fog event. If this issue is not resolved, including other uncertainties, e.g., related to nucleation processes, there is a large uncertainty in the fog formation and prediction for its dissipation (Bott et al. 1990; Gultepe et al. 2016b).

\section{- Scale issues/turbulence}

Atmospheric processes are time dependent and this dependency must be considered in the algorithms; otherwise, an underestimation of the physical terms is possible over the shorter time scales. For example, vertical air velocities $\left(w_{a}\right)$ and turbulence $\left(w^{\prime}\right)$ effects on ice particle populations can be large over short time scales (Dryden 1956).

\section{- Cold bias in numerical model simulations}

Many NWPs have issues with accurate prediction of the BL temperature and moisture profiles, the advection terms that affect ice fog or ice cloud microphysics and visibilities. Cold biases and high relative humidity (RH) biases predicted from NWPs (Sun et al. 2003) can lead to an overestimation of fog occurrences. Cold biases of more than $-2{ }^{\circ} \mathrm{C}$ are also noted over maritime 
environments (Misra et al. 2008) that can affect climate-based prediction. Therefore, NWPs need to be adjusted physically or empirically to improve $\mathrm{T}$ and RH predictions. Another reason for the prediction issues over marine environments can be related to wind speed and directional issues/ uncertainties.

- Synoptic scale processes and advection of moisture Large-scale systems are important for creating conditions favorable to the formation of ice fog or ice cloud and dissipation in the absence of a frontal system. A timely prediction of high-pressure systems over cold climates and generation of a $\mathrm{BL}$ inversion can play an important role in ice fog/cloud formation (Bowling et al. 1968; Gultepe et al. 2015). On the other hand, over marine environments, advection of moist and warm air over a cold ocean or land surface can also generate fog and low-level ice clouds (or supercooled fog clouds) (Gultepe 2015). Therefore, initialization of NWPs with large-scale models needs to be improved for better prediction of ice fog or ice cloud.

\section{- Surface-atmosphere interactions}

Ice fog and ice cloud formation are not only a function of temperature, but also moisture content in the ABL that is related to the ocean surface vapor, cracked ice, wet vegetation, and forests. Turbulent heat and moisture fluxes over wet surfaces play an important role in fog formation (Gultepe et al. 2016a; Gultepe 2015; Vihma et al. 2014). In particular, in marine environments and mountainous regions, atmosphere-surface interactions need to be properly understood (Fernando et al. 2015). Although these issues are resolved in three-dimensional ice fog or cloud models, they are not currently applicable to large-scale NWP predictions, and these are computationally expensive. Because of this, both numerical and physical process improvements in the NWPs are needed for accurate ice fog or cloud predictions.

- Representation of physical processes at various simulation scales

Physical processes in models are often designed for certain space scales and are time dependent. When a parameterization is developed for a special scale of approximately $50 \mathrm{~km}$, it cannot be used for other scales unless the system studied is very homogeneous. Therefore, empirical and physical parameterizations should be improved or the dependence of the physical processes on the scale needs to be adjusted (Tao et al. 2009; Mailhot et al. 2014). Otherwise, when considering ice fog occurrence over shorter time scales, prediction of fog intensity along with a timely prediction of the location will not be reliable. Therefore, issues in the microphysical parameterizations related to averaging scales need to be improved.

- Aircraft produced ice particles (APIPs)

Aircraft contrails are often visible and occur at high altitudes and cold temperatures, but over the northern latitudes these contrails are clearly visible in the ABL over the airports (Heymsfield 2011; Schumann and Heymsfield. 2016; Gultepe et al. 2014, 2015). Aircraft-produced ice particles (APIPs) in supercooled cloud conditions can be seen over the airports or behind aircraft (Heymsfield et al. 2011; Woodley et al. 1991; Langmuir et al. 1948; Ludlam 1956). Heymsfield et al. (2011) stated that the holes in clouds are due to inadvertent seeding of clouds with ice particles generated by aircraft, produced through spontaneous freezing of cloud droplets in air that is cooled as it flows around an aircraft propeller tip or jet aircraft wings. They assert that polar clouds are particularly susceptible to the APIPs effects because of modifications in the radiative processes. This may also suggest that ice crystals sampled by aircraft probes over the Arctic environment may include APIPs.

The issues stated above regarding the modeling and observing of cold fog and ice clouds are important for operational applications. Retrieving fog properties from remote sensing measurements requires various assumptions based on particle size distributions, along with statistical and empirical relationships (Minnis et al. 1993, b; Lin et al. 1983). The assumptions are also used in remote sensing retrievals that are similar to the modeling applications of the ice fog or ice clouds in the ABL for both NWPs and climate models.

To further study open questions related to cold fog and ice cloud prediction, new technologies developed for instrumentation and remote sensing must be tested 
and then applied in the NWP and climate models. The research on ice fog and ice clouds presented here suggests that the accurate forecast and nowcast of cold fog or ice clouds using numerical models and remote sensing techniques remains difficult and needs to be addressed. Presently, because of issues related to ice nucleation and microphysical processes, typical numerical forecast and climate models cannot be used accurately for obtaining cold fog and ice cloud profiles. These models usually lack sufficient resolution and appropriate physical parameterizations to study these clouds. Many models do not accurately forecast fog intensity (e.g., the visibility) because of the lack of $N_{\mathrm{i}}$ information, or, indeed, $N_{\mathrm{i}}$ is not even considered.

Cold fog and ice clouds overall are important because of their impact on aviation, transportation, marine environments, sportive activities, climate, and ecosystem. In Canada, on average 2080 motor vehicle collisions occur per year due to reduced visibility, resulting in 3015 injuries and 71 fatalities (Transport Canada, 2016). Due to low visibility conditions, about 600 fatal accidents occur every year in the USA. When comparing accident statistics to all other precipitation types, fog-related accidents occur ten times more than other types of accidents (Hamilton et al. 2014). This special issue points out that NWP model improvements are needed; then, integrated prediction systems including remote sensing platforms and NWP outputs should be developed. The three-dimensional fog models or large eddy simulation (LES) models are currently not practical to be used operationally, because the time consuming numerical algorithms can delay the availability of the simulations and are computationally expensive (Wissmeier et al. 2013). On the fog hazard side, better forecasts are expected to help mitigate the financial losses and reduce injuries caused by fog in air, sea, and road traffic.

There are important feedback mechanisms between cold fog formation and ice cloud nucleation processes. The present cloud models are designed to obtain the correct cloud physical parameters such as precipitation amount and IWC, but high ice crystal number concentration values for ice fog conditions cannot be predicted using current IN parameterizations such as the results presented in Murray et al.
(2012) and Gultepe et al. (2016b). In addition, the number concentration of $\mathrm{CCN}$ and IN and their chemical composition impact the total ice crystal number concentration and PSD, and eventually these affect the visibility during hazy and foggy conditions. Therefore, urban fog studies and decadal trend analyses of the visibility on various continents may not be studied properly. Global change processes, including regional air pollution issues, exhibit a strong influence on fog because of a lack of understanding of IN processes that include homogenous ice nucleation (HIN). The HIN can occur at very cold temperatures $\left(\sim-40{ }^{\circ} \mathrm{C}\right.$ ) and needs to be explored specifically for a high number of ice crystal concentrations for ice fog events over the Arctic environments (Heymsfield et al. 2005; Heymsfield and Sabin 1989; Heymsfield and Miloshevich 1993; Gultepe et al. 2016b). In fact, visibility is still considered as only a function of IWC (or LWC) in NWPs, Stoelinga and Warner (1999) and this needs to be improved.

Prediction of ice fog and ice clouds based on analysis methods needs to be further developed because surface observations are too sparsely distributed to adequately capture the temporal and spatial variability of fog. Sensors are usually not calibrated for cold climatic regions $\left(<-10{ }^{\circ} \mathrm{C}\right)$. Similarly, satellite imagery and cloud radars cannot provide the necessary information on spatial variability and have serious limitations due to their temporal resolution and spatial coverage. In the presence of mid- and high-level clouds, satellite techniques cannot be useful for low-level ice cloud detection and monitoring (Gultepe et al. 2007). Surface observations in principle can easily detect the fog events, but there are not many surface sites that include the necessary novel sensors such as liquid water content sensors, fog droplet spectrometers, cloud radars, profiling microwave radiometers, and ceilometers, for detecting ice fog and ice clouds in BL (Gultepe et al. 2015). Fog is not a continuous phenomenon in space and time, and that requires a detailed analysis of the boundary layer structure, atmospheric stability, radiative fluxes, mixing conditions, and state of turbulence. Integrated methods are required to combine all key variables for forecasting and nowcasting applications. When observations are integrated with numerical model 
output, better methods for fog nowcasting and forecasting can be developed, but the lack of surface observations may still result in important problems for fog prediction because of scale issues and limited knowledge related to physical and radiative process.

The papers in this volume addressing the several issues related to IN processes, dynamics of the systems, instrumental conditions, temporal variability, ice fog and ice cloud occurrence statistics, and visibility are provided. In reality, freezing fog and ice fog can occur often over the cold climates, particularly in the high Arctic and Antarctic regions, and over cold pools generated in mountain valleys. These fog types and low-level ice clouds can create adverse weather conditions for aviation, transportation, and marine applications. Climate change occurrence can also generate cold fog conditions over the poles that can affect Arctic passages during transition seasons and winter conditions that need to be considered for future Arctic environmental planning.

We gratefully acknowledge the funding and support for Dr. I. Gultepe from the Canadian National Search and Rescue (SAR) Secretariat and many contributions from the US side, especially to Dr. H.J.S. Fernando from the University of Notre Dame (UND), USA, as scientific contributors to this topical issue, as well as the science team members of the SAAWSO and MATERHORN projects, respectively. Additionally, we would like to thank many reviewers for their hard work in evaluating the manuscript and making suggestions for improvements.

\section{REFERENCES}

Baumgardner, D., McFarquhar, G., \& Heymsfield, A. J. (2016). Ice formation and evolution in clouds and precipitation: Measurement and modeling challenges. AMS Monographs (in press).

Bott, A., Sievers, U., \& Zdunkowski, W. (1990). A radiation fog model with a detailed treatment of the interaction between radiative transfer and fog microphysics. Journal of the Atmospheric Sciences, 47, 2153-2166.

Bowling, S. A., Ohtake, T., \& Benson, C. S. (1968). Winter pressure systems and ice fog in Fairbanks, Alaska. Journal of Applied Meteorology, 7, 961-968.

Dryden, W. A. (1956). Effects of the scale of spatial averaging on the kinetic energies of small-scale turbulent motion. Journal of Meteorology, 14, 287-292.
Fernando, H. J. S., Pardyjak, E. R., Di Sabatino, S., Chow, F. K., De Wekker, S. F. J., Hoch, S. W., et al. (2015). The MATERHORN: Unraveling the intricacies of mountain weather. Bulletin of the American Meteorological Society, 96, 1945-1967.

Gultepe, I. (2015). Mountain weather: observations and modeling. Advances in Geophysics, 56, 229-312.

Gultepe, I., Fernando, H. J. S., Pardyjak, E., Hoch, S. W., Silver, Z., Creegan, E. D., et al. (2016a). Mountain ice fog: Observations and predictability. Pure and Applied Geophysic,. doi:10.1007/ s00024-016-1374-0.

Gultepe, I., Heymsfield, A.J., Field, P., \& Axisa, D. (2016a). Ice phase precipitation. Chapter 6 in ice formation and evolution in clouds and precipitation: Measurement and modeling challenges. In: D. Baumgardner, G. McFarquhar, A. J. Heymsfield (Eds.), AMS Monographs (in press).

Gultepe, I., Heymsfield, A.J., Gallagher, M., \& Ickes, L. (2016b). Ice fog. Chapter 4 in ice formation and evolution in clouds and precipitation: Measurement and modeling challenges. In: D. Baumgardner, G. McFarquhar, \& A. J. Heymsfield (Eds.), AMS Monographs (in press).

Gultepe, I., Kuhn, T., Pavolonis, M., Calvert, C., Gurka, J., Isaac, G. A., et al. (2014). Ice fog in arctic during FRAM-IF project: Aviation and nowcasting applications. Bulletin of the American Meteorological Society, 95, 211-226.

Gultepe, I., Pawgoski, M., \& Reid, J. (2007). Using surface data to validate a satellite based fog detection scheme. Weather and Forecasting, 22, 444-456.

Gultepe, I., Zhou, B., Milbrandt, J., Bott, A., Li, Y., Heymsfield, A. J., et al. (2015). A review on ice fog measurements and modeling. Atmospheric Research, 151, 2-19.

Hamilton, B., Tefft, B., Arnold, L., \& Grabowski, J. (2014). Hidden highways: Fog and traffic crashes on America's roads. Washington, DC: Published by AAA Foundation for Traffic Safety.

Harrington, J. Y., Sulia, K., \& Morrison, H. (2013a). A method for adaptive habit prediction in bulk microphysical models. Part I: theoretical development. Journal of the Atmospheric Sciences, $70,349-364$.

Heymsfield, A. J., Kennedy, P. C., Massie, S., Schmitt, C., Wang, Z., Haimov, S., \& Rangno, A. (2010). Aircraft-induced hole punch and canal clouds: inadvertent cloud seeding. Bulletin of the American Meteorological Society, 91, 753-766.

Harrington, J. Y., Sulia, K., \& Morrison, H. (2013b). A method for adaptive habit prediction in bulk microphysical models. Part II: parcel model corroboration. Journal of the Atmospheric Sciences, $70,365-376$.

Heymsfield, A., \& Miloshevich, L. M. (1993). Homogeneous ice nucleation and supercooled liquid water in orographic wave clouds. Journal of the Atmospheric Sciences, 50, 2335-2353.

Heymsfield, A. J., \& Sabin, R. M. (1989). Cirrus crystal nucleation by homogeneous freezing of solution drops. Journal of the Atmospheric Sciences, 46, 2252-2264.

Heymsfield, A., Schmitt, C., Bansemer, A., Twohy, C., Poellot, M., Fridlind, A., et al. (2005). Homogeneous ice nucleation in subtropical and tropical convection and its influence on cirrus anvil microphysics. Journal of the Atmospheric Sciences, 62, 41-64.

Heymsfield, A. J., Thompson, G., Morrison, H., Bansemer, A., Rasmussen, R. M., Minnis, P., et al. (2011). Formation and spread of aircraft-induced holes in clouds. Science AAAS, 333, $77-81$.

Langmuir, I., Schaefer, V. J., Vonnegut, B., Maynard, K., SmithJohannsen, R., Blanchard, D., \& Falconer, R. E. (1948). Final 
reports, Project Cirrus, RL140. General Electric Res. Lab. Req 21190 with the Depart. Of the Army Project: 3-99-07-022, pp 119.

Lawson, R. P., Baker, B. A., Zmarzly, P., O'Connor, D., Mo, Q., Gayet, J. F., et al. (2006). Microphysical and optical properties of atmospheric ice crystals at South Pole station. Journal of Applied Meteorology and Climatology, 45, 1505-1524.

Lin, Y. L., Farley, R. D., \& Orville, H. D. (1983). Bulk parameterization of the snow field in a cloud model. Journal of Climate and Applied Meteorology, 22, 1065-1092.

Ludlam, F. H. (1956). Fall-streak holes. Weather, 11, 89-90.

Mailhot, J., Milbrandt, J., Giguère, A., McTaggart-Cowan, R., Erfani, A., \& Denis, B. (2014). An experimental high-resolution forecast system during the Vancouver 2010 Winter Olympic and Paralympic Games. Pure and Applied Geophysics, 171, 209-229.

McMillen, J. D., \& Steenburgh, W. J. (2015). Impact of microphysics parameterizations on simulations of the 27 October 2010 Great Salt Lake-effect snowstorm. Weather and Forecasting, 30, 136-151.

Milbrandt, J. A., \& Morrison, H. (2016). Parameterization of cloud microphysics based on the prediction of bulk ice particle properties. Part III: Introduction of multiple free categories. Journal of the Atmospheric Sciences, 73, 975-995.

Minnis, P., Heck, W., \& Young, D. F. (1993a). Inference of cirrus cloud properties using satellite-observed visible and infrared radiances. Part II: Verification of theoretical cirrus radiative properties. Journal of the Atmospheric Sciences, 50, 1305-1322.

Minnis, P., Liou, K. N., \& Takano, Y. (1993b). Inference of cirrus cloud properties using satellite-observed visible and infrared radiances. Part I: Parameterization of radiance fields. Journal of the Atmospheric Sciences, 50, 1279-1304.

Misra, V., Marx, L., Brunke, M., \& Zeng, X. (2008). The equatorial Pacific cold tongue bias in a coupled climate model. Journal of Climate, 21, 5852-5869.

Morrison, H., \& Milbrandt, J. A. (2015). Parameterization of cloud microphysics based on the prediction of bulk ice particle properties. Part I: Scheme description and idealized tests. Journal of the Atmospheric Sciences, 72, 287-311.
Morrison, H., Milbrandt, J. A., Bryan, G. H., Ikeda, K., Tessendorf, S. A., \& Thompson, G. (2015). Parameterization of Cloud microphysics based on the prediction of bulk ice particle properties. Part II: Case study comparisons with observations and other schemes. Journal of the Atmospheric Sciences, 72, 312-339.

Murray, B. J., O'Sullivan, D., Atkinson, J. D., \& Webb, M. E. (2012). Ice nucleation by particles immersed in supercooled cloud droplets. Chemical Society Reviews, 41, 6519-6554.

Schumann, U., \& Heymsfield, A. J. (2016). On the lifecycle of individual contrails and contrail cirrus. Chapter in ice formation and evolution in clouds and precipitation: Measurement and modeling challenges. D. Baumgardner, G. McFarquhar, \& A. J. Heymsfield (Eds.), AMS Monographs (in press).

Stoelinga, M. T., \& Warner, T. T. (1999). Nonhydrostatic, mesobeta scale model simulations of cloud ceiling and visibility for an east coast winter precipitation event. Journal of Applied Meteorology, 38, 385-404.

Sun, B., Yu, L., \& Weller, R. (2003). Comparisons of surface meteorology and turbulent heat fluxes over the Atlantic: NWP model analyses versus Moored Buoy observations. Journal of Climate, 16, 679-695.

Tao, W. K., Lau, W., Simpson, J., Chern, J. D., Atlas, R., Randall, D., et al. (2009). A multiscale modeling system: Developments, applications, and critical issues. Bulletin of the American Meteorological Society, 90, 515-534.

Vihma, T., et al. (2014). Advances in understanding and parameterization of small-scale physical processes in the marine Arctic climate system: A review. Atmospheric Chemistry and Physics, 14, 9403-9450.

Wissmeier, U., Buras, R., \& Mayerpa, B. (2013). paNTICA: A fast $3 \mathrm{D}$ radiative transfer scheme to calculate surface solar irradiance for NWP and LES models. Journal of Applied Meteorology and Climatology, 52, 1696-1715.

Woodley, W. L., Henderson, T. J., Vonnegut, B., Gordon, G., Breidenthal, R., \& Holle, S. M. (1991). Aircraft-produced ice particles (APIPs) in supercooled clouds and the probable mechanism for their production. Journal of Applied Meteorology, 30, 1469-1489. 